\title{
UN ESPACIO DE CULTO RURAL ROMANO EN MONTESA, COMARCA de LA Costera, VALENCIA
}

Este estudio se centra en un yacimiento rural localizado en la partida de El Canari de Montesa, en la comarca de La Costera, Valencia. Allí se han encontrado una serie de estructuras y niveles arqueológicos que podrían ser asimilados a un espacio de culto romano en uso desde la segunda mitad del s. II a.C. hasta mediados de s. I d.C. Asimismo, en su entorno, se han hallado otras estructuras relacionadas con el abancalado de campos para el cultivo.

Palabras clave: comarca de La Costera, lugar de culto rural romano, agricultura y colonización romanas.

\section{An area for Roman rural cult in Montesa (La Costera, Valencia)}

This study focuses on a rural site located in the partdida de El Canari of Montesa, in the shire of La Costera, Valencia. There we found a number of structures and archaeological levels that can be assimilated to a Roman place of religious worship which was in use from the second half of the second century BC to mid-first century AD. Also, in the surrounding area, we have found other structures related to the terraced fields for cultivation.

Key words: shire of La Costera, Roman rural religious worship, agriculture and Roman colonization.

La zona de estudio se ubica en la comarca de la Costera (Valencia), en torno a las parcelas 25, 26 y 27 del Polígono 2 de Montesa, en la partida del Canari, a los pies de la Lloma Ampla y entre el camí d'Anna y el de l'Alcudia; dos caminos al $\mathrm{N}$ del río Canyoles que discurren paralelos por el valle medio-bajo del río (Pascual y García Borja 2010). No está en un lugar especialmente estratégico desde el punto de vista del control del territorio pues sólo domina la parte del valle que se encuentra inmediatamente frente al yacimiento. Actualmente, todo el entorno está profundamente transformado y adaptado para el cultivo de cítricos y otros frutales de reciente implantación. Sin embargo, las parcelas a que nos referimos se encontraban incultas y no habían sufrido modificaciones desde el momento en que se abandonaron, a mediados del siglo pasado, cuando todavía eran usadas para los cultivos propios de secano.

Para centrar los trabajos de excavación se realizaron una serie de zanjas. Estas trincheras fueron planteadas de manera estratégica en diferentes zonas del área que pretendíamos analizar de tal forma que, con todas ellas, pudiéramos obtener una visión de conjunto que ayudase a delimitar el yacimiento y permitiera, en su caso, descartar aquellos lugares en los que era improbable que hubiera restos arqueológicos. Tras los trabajos mecánicos se identificaron tres sectores (A, B y C) en los que aparecieron estructuras asociadas a niveles arqueológicos (fig. 1). 


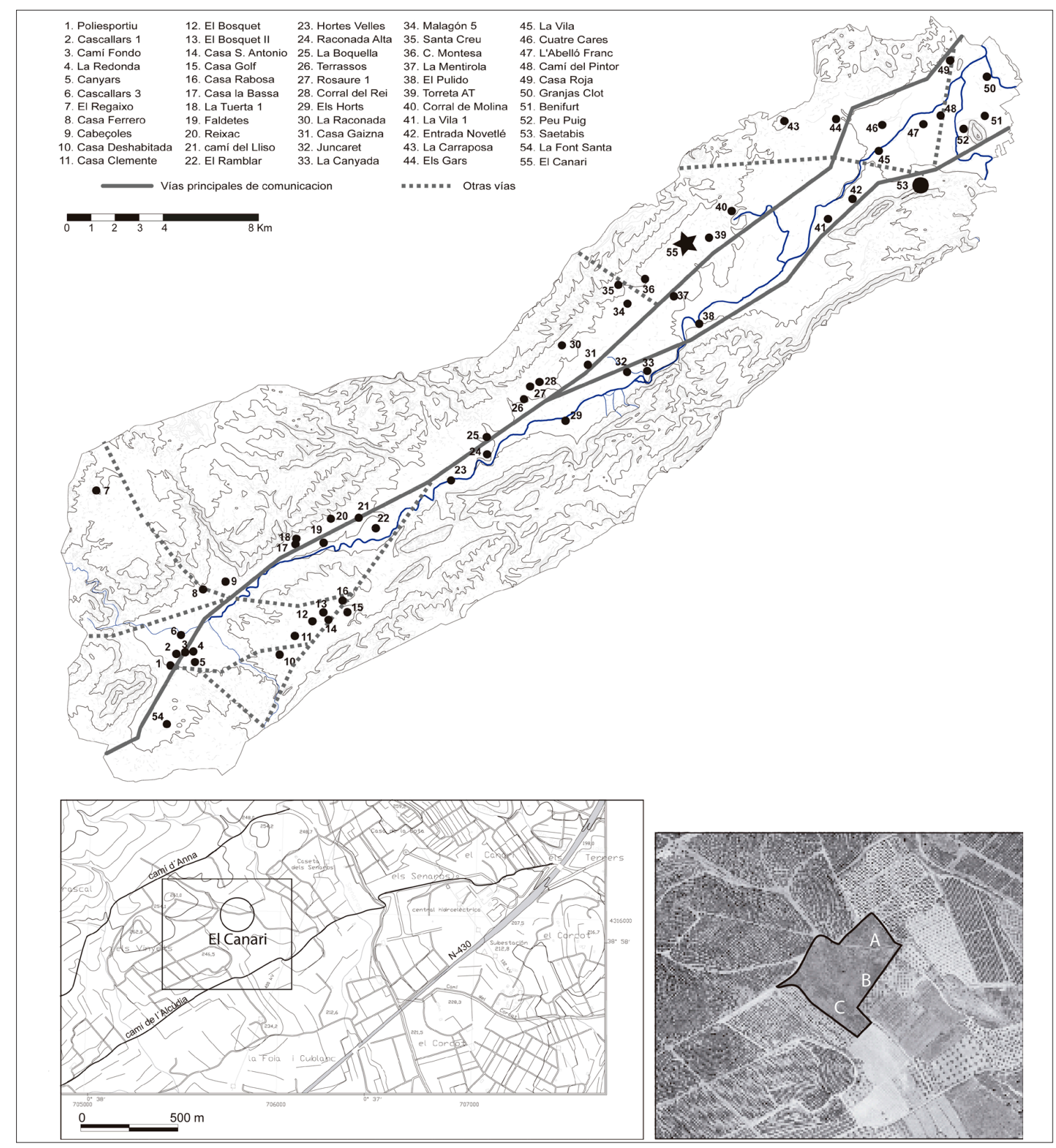

Fig. 1. Localización del yacimiento en el valle del Canyoles con indicación de las vías principales de comunicación y los yacimientos romanos conocidos. Sectores en que se ha dividido la superficie estudiada.

\section{SECTOR A. POLÍGONO 2, PARCELA 25 (MONTESA)}

Durante los trabajos de limpieza y delimitación se encontraron restos de estructuras y niveles arqueológicos correspondientes a un hábitat rural fechado entre los ss. II a.C. y II d.C. Se localizaban al S de la parcela, estaban muy arrasados y a nivel de cimentaciones, por lo que presumiblemente sólo quedaban restos de estructuras negativas o, al menos, nada que conservase alzados a partir de la cota del suelo que hubo en el momento de uso de las estructuras que han llegado hasta nosotros. 


\section{SECTOR B. POLÍGONO 2, PARCELA 26 (MONTESA)}

Se documentó la existencia de una alineación de piedras NE-SO localizada al SE de la parcela. En algunos tramos presentaba un frente más o menos dispuesto ordenadamente en su cara oriental. Tenía un alzado de aproximadamente $50 \mathrm{~cm}$ y se adaptaba a una curva de nivel. Asociado a ella se encontraba un paleosuelo de color marrón oscuro con presencia de fragmentos cerámicos de los ss. II a.C. al II d.C.

\section{SECTOR C. POLÍGONO 2, PARCELA 27 (MONTESA)}

También, en este sector, descubrimos una alineación de piedras E-O que se encontraba en el centro de la parcela y a la que se le asociaba un paleosuelo de color marrón oscuro, con presencia de materiales arqueológicos de una cronología que comprende desde el s. II a.C. hasta el II d.C.

\section{LOS HALLAZGOS DEL SECTOR A}

El nivel superficial correspondía a una capa de 30-40 $\mathrm{cm}$ caracterizada por ser una tierra margo-arcillosa de color pardo, apelmazada por el abandono de los campos y reconquistada por vegetación mediterránea de bosque bajo. Por debajo aparecía una tierra margosa, de color más claro, sin inclusiones de ningún tipo salvo en el área donde se concentran restos de una actividad humana antigua, en la que, además de presentar piedras y cantos de tamaño mediano, aparecían manchas en el sedimento de color gris, negro, naranja y marrón oscuro concentradas en diferentes lugares y se difuminan por la superficie en función de los arrastres realizados por los arados. Esta capa, correspondía, por tanto, a tierras revueltas. Se comenzó a realizar un registro sistemático a partir del momento en que las huellas de arado eran apreciables en el suelo y, en realidad, implicaba un gran nivel con abundante presencia de materiales arqueológicos mezclados que cubría a las estructuras y niveles que, por diferentes motivos, no fueron desmantelados a consecuencia del cultivo de los campos. La mayor parte de los niveles presentaba una tonalidad anaranjada; lo que sugiere que probablemente buena parte de los alzados de los muros que hubo fueran de adobe. En este sentido, junto a uno de los cimientos, aparecieron dos fragmentos de adobes. En algunos rellenos también se encontraron restos de adobes y los niveles superficiales de una gran fosa, que más adelante estudiaremos, estaban formados fundamentalmente por adobes descompuestos.

La mayor parte de las alineaciones que se pudieron documentar no superaba los $30 \mathrm{~cm}$ de alzado. Para realizarlas se utilizaron mampuestos y cantos procedentes de un afloramiento natural que se encuentra en el mismo lugar en que se erigieron.

La obra de fábrica de todas ellas correspondía a una mampostería en seco favoreciendo el asiento de las piezas con ripios, barro y tierra. En general presentaban un ancho de $50-52 \mathrm{~cm}$ y la mayor parte de ellas tenía en torno a $1 \mathrm{~m}$ de longitud, excepción hecha de los muros y estructuras de la zona sudoeste. Aunque el nivel de arrasamiento es muy alto y su escasa longitud pueda deberse a remociones de tierra producidas por arados, lo cierto es que cuando se han conservado sus zanjas de cimentación, éstas, nunca han ido más allá de los propios límites de la estructura que podíamos documentar en planta, lo cual invita a pensar en la posibilidad de que, en realidad, éstas tuvieran únicamente esa envergadura. En cuanto a la distribución de los restos estructurales podemos diferenciar dos áreas. Una situada al NE y otra al SO de una gran fosa (Fosa A) de planta circular (fig. 2).

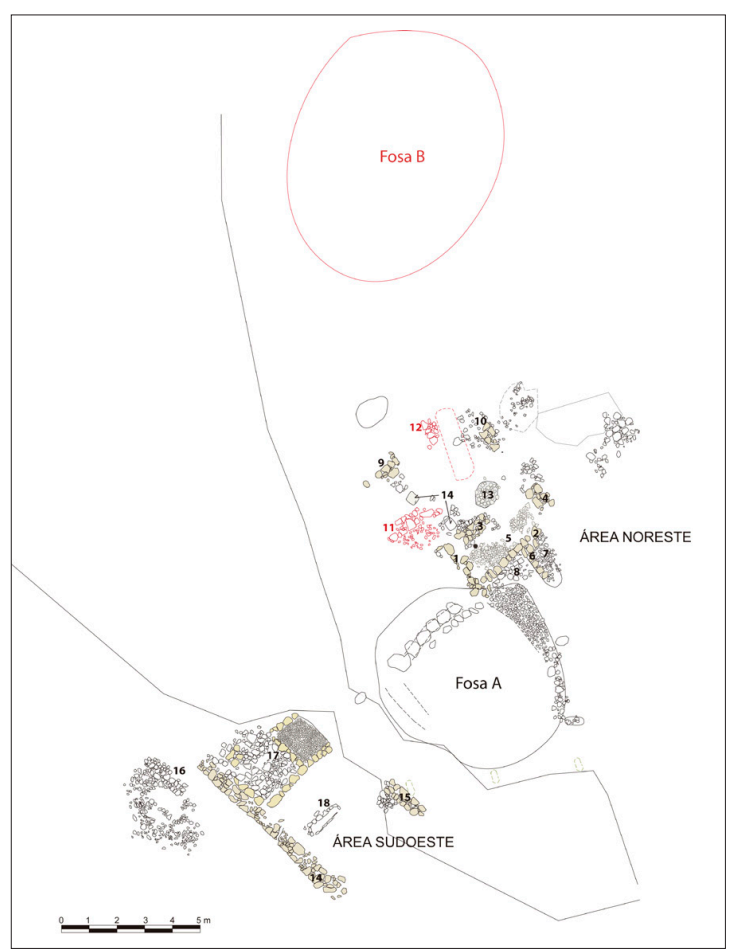

Fig. 2. Planta de las estructuras localizadas en el Sector A. 


\section{EL ÁREA NORESTE}

De las estructuras que allí se localizaban podemos decir que estaban muy arrasadas y que prácticamente no llegaron hasta nosotros niveles arqueológicos intactos asociados a ellas. Como ya hemos indicado, se trataba de pequeñas alineaciones de mampostería en seco que, tanto por su técnica como por sus dimensiones, no se diferencian entre ellas. Únicamente dos parecían distintas pues presentaban una única hilada de sillares que, además, eran ligeramente más grandes que los del resto de estructuras (fig. 2, 1 y 2). Estos cimientos, junto a otros dos (fig. 2, 2 y 4), parecían delimitar un espacio rectangular de 3,10 m por 1,20 m en el que había una superficie, más o menos horizontal, realizada a base de ripios dispuestos sobre un relleno que servía para nivelar depresiones del terreno o vacíos dejados por estructuras más antiguas como podríamos interpretar del hecho de que, por debajo, hubiera un agujero de poste (fig. 2, 5). Nos encontramos también, por tanto, en un nivel que en el momento de ocupación debió situarse por debajo del suelo de habitación y que probablemente sirviera como asiento del suelo original. No obstante, este es uno de los pocos niveles que han llegado hasta nosotros sin remover y se puede datar entre el 0 y el 30 d.C. por la presencia de TSI (fig. 3,1 ).

Al SE del espacio rectangular había una alineación de piedras (fig. 2,6). En el relleno de su zanja aparecieron materiales que, a grosso modo, ofrecían una cronología ibero romana (fig. 3,2 a 7), con arranque a mediados del

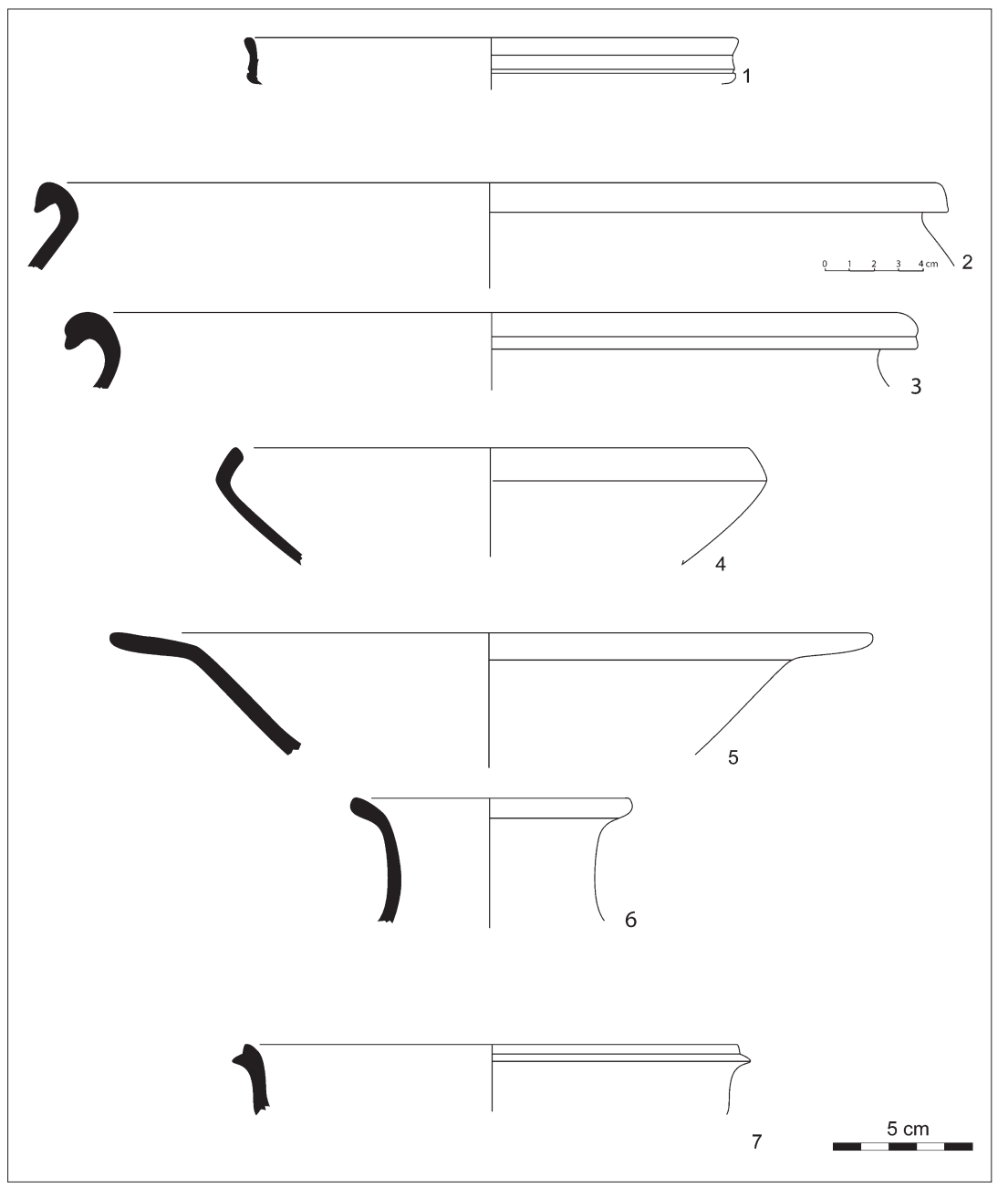

Fig. 3. Materiales recuperados de las zanjas de los muros de las estructuras del Sector A. 
s. II a.C. debido a la presencia de varios fragmentos de ánfora grecoitálica de pasta campana. También aparecieron unos niveles situados a ambos lados del cimiento que estaban compuestos por piedras de tamaño mediano, ligera pendiente hacia el sur y una tonalidad anaranjada que daba fe de la presencia de adobes. En el primero (fig. 2, 7), aparecieron fragmentos de dolium y otros grandes contenedores mientras que en el otro (fig. 2,8), además de materiales de mediados del s. II a.C, había fragmentos de paredes finas del tipo cáscara de huevo que se engloban en época claudia. Es difícil dar una interpretación a estos conjuntos, aunque por las características de los mismos parecen corresponder al desmoronamiento de una pared de piedras y adobe o que obedezcan a una funcionalidad similar a la de la superficie de ripios descrita antes. En cualquier caso, lo que parece indudable es que su formación también se produjo en la primera mitad del s. I d.C. (fig. 4).

$\mathrm{Al} \mathrm{N}$ de esta estancia encontramos otros cimientos de mampuestos con distintas alineaciones y muy arrasados (fig. 2, 9 a 12). Esta diferencia en las alineaciones parece indicar que nos encontramos ante estructuras correspondientes a varias fases que, por tanto, mostrarían una ocupación prolongada del lugar con distintos momentos constructivos o remodelaciones de un mismo espacio. En este sentido, la proyección hipotética de dos de ellas (fig. 2, 9 y 10) muestran una disposición ortogonal en relación a la estancia descrita más arriba, por lo que se podrían asociar a la misma y, en conjunto, ofrecerían la planta de un pequeño edificio de planta rectangular de 5,90 m de largo por 4,45 de ancho dividido en dos espacios, uno al $\mathrm{S}$ definido por la superficie de ripios y otro al $\mathrm{N}$.

Ese espacio situado al $\mathrm{N}$ se caracterizaría por la presencia de un nivel que comenzó a documentarse inmediatamente por debajo del superficial y aparecía como una gran mancha gris, de planta circular cortada y arrastrada por arados. Tras eliminar sus primeros centímetros de potencia, comenzó a definirse una estructura excavada en el suelo, de planta circular y rellena a base de piedras y cantos medianos mezclados en una tierra margo-arcillosa de color gris oscuro que hemos interpretado como un hogar (fig. 2,13). Entre los materiales recuperados en su desmonte aparecieron fragmentos de cerámica iberorromana, el borde de una copa Mata 3821 , paredes finas y la base de una pátera de TSI, probablemente de Pisa, con el sello ATEI que nos situaría entre el 10 y el 25 d.C. (fig. 5).

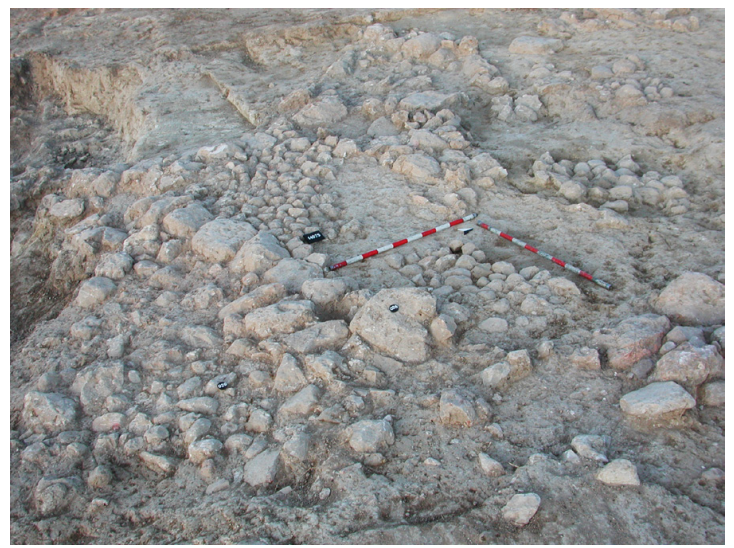

Fig. 4. Visión de conjunto de las estructuras del s. I d.C.

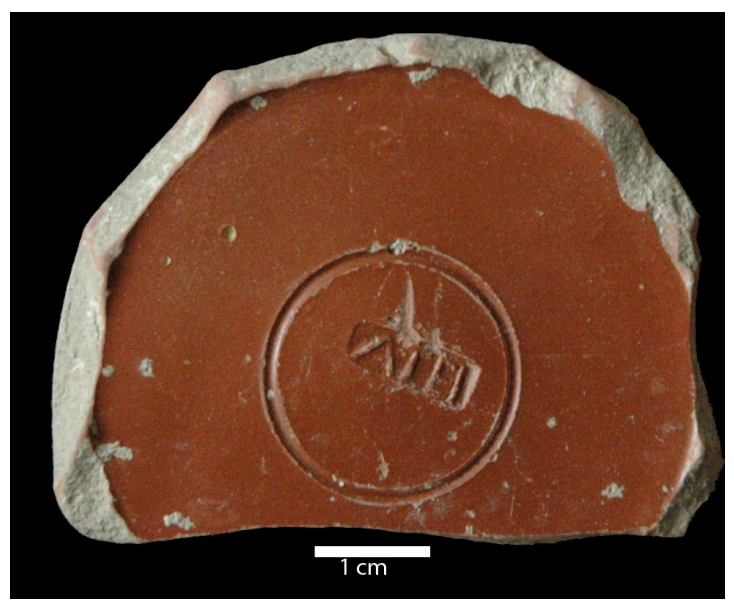

Fig. 5. Plato de TSI con la marca de alfarero ATEI correspondiente al taller, probablemente pisano, de CN ATEIVS (10-25 d.C.).

Por otra parte, este nuevo espacio definido al $\mathrm{N}$ pudo estar abierto por su lado O. Allí se encontraron dos bloques de piedra trabajada de planta más o menos cuadrada y unas dimensiones de aproximadamente $40 \times 40 \mathrm{~cm}$ que parecían corresponder a la base de unos postes, jambas, pilares o columnas que proponemos fueran de madera ya que no se ha recuperado ningún elemento que permita intuir la existencia de columnas de piedra (fig. 2, 14).

Existen, además, dos cimientos de mampostería en seco que no parecen guardar relación aparente con el edificio que hemos descrito (fig. 2, 11 y 12). Desde el punto de vista morfológico y constructivo no se diferencian de las del resto. Sin embargo, sus alineaciones no guardan relación alguna con aquel, por lo que pensamos que se 
trata de elementos correspondientes a una fase anterior que probablemente debamos relacionar con otra gran fosa localizada al $\mathrm{N}$ del sector cuya cronología abarcaría desde mediados del s. II a.C. hasta el cambio de era como más adelante veremos (Fosa B). En este sentido, los rellenos asociados a esos cimientos proporcionaron varios fragmentos de ánfora itálica de pasta campana y de cerámicas ibéricas e iberorromanas atribuibles a una cronología tardorrepublicana.

\section{LAS FOSAS DEL SECTOR A}

La fosa $\mathrm{A}$ se encontraba inmediatamente al $\mathrm{S}$ de las estructuras referidas en el capítulo anterior, tenía 7 × $6 \mathrm{~m}$, era de planta ovalada y estaba excavada en el suelo y ligeramente ensanchada y escalonada por sus lados O, E y $\mathrm{N}$. Coincidiendo con el escalón del $\mathrm{N}$ se encontraron dos hiladas de piedras superpuestas. La más reciente estaba formada con piedras de tamaño mediano, alineadas y dispuestas en seco. Por debajo, había otra hecha a base de grandes bloques de piedra. Parecen corresponder a acondicionamientos del lugar a lo largo del tiempo que éste estuvo en uso.

La fosa constaba de varios rellenos. Los superficiales se caracterizaban por tener un color anaranjado a consecuencia de la presencia de adobes descompuestos que se habían ido depositando paulatinamente. Esta secuencia de niveles, cubría a otro gran nivel de color gris oscuro, con abundantes cenizas y una relativa presencia de carbones. De él se recuperó un interesante conjunto de materiales que abarcan una amplia cronología desde el s. I a.C.

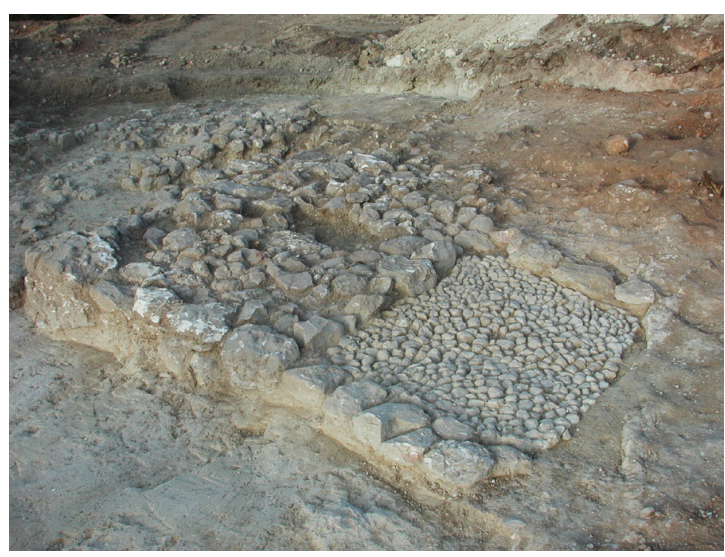

Fig. 6. Construcción de planta rectangular en el área O del sector A identificada como altar. hasta época de Claudio con elementos que, en ningún momento, van más allá de la década de los 50 d.C. y que se caracterizaban por aparecer, aunque esparcidos por toda la fosa, en pequeñas concentraciones al $\mathrm{S}$ de las hiladas de piedras mencionadas.

La fosa B se localizaba al $\mathrm{N}$ de las estructuras. Estaba excavada en el suelo, de planta igualmente ovalada y presentaba unas dimensiones de $9 \times 6 \mathrm{~m}$ aproximadamente. Tenía un relleno margoso, de tonalidad predominantemente blanca aunque, sobre todo al $\mathrm{O}$, era de color marrón claro. También hacia el $\mathrm{O}$ se concentraba una importante agrupación de piedras, cantos y bloques de diferentes tamaños sin organización alguna incluidos en una tierra margosa muy compacta. Los materiales que se recuperaron de la misma tienen una cronología de la segunda mitad del s. II a.C. hasta el cambio de era o, incluso, un momento algo anterior. Su amortización viene determinada por la presencia, junto a los materiales típicos de época tardorrepublicana, de un asa de ánfora Dressel 2/4 y la base de un plato de TSI característica de los momentos finales del s. I a.C.

\section{EL ÁREA SUROESTE}

Al SO de la fosa A y, por tanto también del área excavada, se encuentra un conjunto de estructuras mejor conservadas que las del área NE, aunque no por ello su estado era bueno. Esta circunstancia podría deberse a que lo robusto de las mismas podría imposibilitar el paso de los arados con facilidad y, probablemente, una parte de este sector ni siquiera fue cultivado.

Los restos conservados de uno de los muros eran los de mayor envergadura en planta y alzado que han llegado hasta nosotros en todo el sector A (fig. 2, 14). Presentaba una longitud conservada de $6,71 \mathrm{~m}$ por un ancho de 50 $55 \mathrm{~cm}$ y un alzado máximo documentado de $68 \mathrm{~cm}$. Los materiales que aparecieron en el relleno de su zanja de cimentación fueron muy escasos y, en general, corresponden a fragmentos cerámicos del ibérico tardío (fig. 3, 7). Los restos de otro muro se localizaban al E del anterior y parecía discurrir en paralelo al mismo (fig. 2, 15). Se encontraba construido sobre el afloramiento natural de piedras y cantos que hemos mencionado más arriba, y sólo han llegado hasta nosotros 1'78 $\mathrm{m}$ de largo por 52 $\mathrm{cm}$ de ancho. Finalmente, al O del mayor de los muros, encontramos un pequeño murete de $1,59 \mathrm{~m}$ de largo por $40 \mathrm{~cm}$ de ancho (fig. 2,16). Es el único de todo el conjunto de muros que presenta un ancho de $40 \mathrm{~cm}$, el menor de 
todos los que se han localizado. Además, tiene una ligera pendiente hacia el $\mathrm{N}$ y se encuentra demasiado cerca $\mathrm{y}$ desalineado en relación al conjunto como para tratarse de un muro como los que hemos visto hasta ahora, lo cual nos hace plantearnos la posibilidad que se trate de un pequeño murete de contención.

Por último, en el área SO del sector A, encontramos una pequeña construcción de planta rectangular y $3,50 \mathrm{~m}$ de largo por un ancho de $2 \mathrm{~m}$ (fig. 2, 17). Apareció directamente bajo el nivel superficial adosada al muro de mayor longitud conservado. Todo el conjunto delimitaba un espacio de planta presumiblemente cuadrangular y a cielo abierto en el que apareció una pequeña estructura rectangular-ovalada de 1,50 m de largo por 45 de ancho y delimitada por piedras (fig. 2, 18).

En cuanto a la primera (fig. 6), estaba formada por un pequeño suelo empedrado de $1,45 \mathrm{~m}$ de ancho por $1,15 \mathrm{~m}$ de largo que se encontraba delimitado por dos alineaciones de piedras al $\mathrm{N}$ y $\mathrm{S}$ respectivamente. Al E quedaba abierto y al $\mathrm{O}$ estaba limitado por una agrupación de piedras con la cual funcionaba. Esta agrupación, de planta cuadrangular, de $2 \times 2,20 \mathrm{~m}$, realizada con piedras de tamaño mediano y algunos bloques dispuestos en las esquinas formaba, junto a la anterior, una única construcción.

\section{CONCLUSIONES E INTERPRETACIÓN DE LAS EXCAVACIONES EN EL SECTOR A. UN POSIBLE LUGAR DE CULTO RURAL ROMANO}

En conjunto, atendiendo a los materiales recuperados en el proceso de excavación arqueológica, podemos decir que hubo dos momentos cronológicos claramente diferenciados. Uno que corresponde a un período comprendido entre la segunda mitad del s. II a.C. y el cambio de era y otro que arrancó en el cambio de era y llegó hasta mediados del s. I d.C.

Todo el conjunto, a excepción de las fosas y el edificio del área $\mathrm{O}$, se encontraba muy arrasado. Ello se debe fundamentalmente a las labores agrícolas desarrolladas en el lugar hasta mediados del s. XX y al uso de arados mecánicos. Todas las estructuras antiguas se encontraban cubiertas por un nivel margoso de color amarillento que es consecuencia de esos arrastres por lo que presenta una gran abundancia de materiales que abarcan una cronología desde la segunda mitad del s. II a.C hasta mediados del I d.C. Entre los más destacables de este nivel superficial encontramos algunos fragmentos de Campaniense A; trozos de ánfora P17, Haltern 70 y Dressel 2/4; varios fragmentos de TSI y TSG, alguno de ellos con sello como más arriba hemos indicado, un fragmento de copita carenada y de mortero del tipo Vegas 7.8; fragmentos de ollas, cerámicas comunes iberorromanas y algunos elementos de construcción escasos; varios pondera, uno de ellos presenta una inscripción, incisa precocción, indicando propiedad y en la que puede leerse POMPI (fig. 7, 1 a) ${ }^{1}$; dos fragmentos de una misma moneda en mal estado de conservación y un as del emperador Claudio fechado entre los años 41 y 51 . En el anverso puede leerse TI CLAVDIVS CAESAR AVG (PMTRPIMP) rodeando el busto descubierto del emperador mirando a izquierda y en el reverso CONSTANTIAE alrededor de una alegoría de la Constancia, SC.

La fosa $\mathrm{B}$, localizada más al $\mathrm{N}$, contenía materiales que van desde mediados del s. II a.C. hasta finales del I a.C. o el cambio de era si bien, predominaban los fragmentos de ánforas. En su base aparecieron depositadas un ánfora ibérica del tipo Ribera I-9, fechada entre el s. II y el inicio del I a.C. (Ribera 2008: fig. 8-7), y una pequeña pátera de borde reentrante (fig. 7, 1). Corresponden al momento inicial de ocupación y son las piezas que fechan el inicio de una actividad en el lugar. Los elementos que datan la amortización de la fosa, por el contrario, son la base de un gran plato de TSI de la forma Consp. 11, fechada entre el 15 a.C. y el 1 d.C. (fig. 7, 2) y un borde de ánfora DR.2/4 que nos situarían en un momento próximo al cambio de era. A esta fosa asociamos las dos cimentaciones (fig. 2, 11 y 12) que no presentan alineación coherente con el resto de estructuras del Sector A y para las que los materiales arqueológicos asociados no van más allá del s. I a.C. Se trata, por tanto, de una fase de ocupación tremendamente arrasada, muy poco documentada y que, atendiendo a los materiales coligados, debió abarcar el período comprendido entre la segunda mitad del s. II a.C. y el cambio de era.

Por el contrario, en la fosa A el relleno estaba formado por cenizas y abundante material arqueológico. La mayor parte de las piezas recuperadas se encontraba fragmentada, aunque un análisis minucioso de los fragmentos permite la reconstrucción total o casi total de varias de ellas.

Fundamentalmente, entre las formas en cerámica ibérica, se encuentran ollas de diferentes tamaños y formas, copas, páteras, botellas y jarros de boca circular, caliciformes, lebetes, kalathoi de pequeño formato y otros con decoración pintada (fig. 7, 3 a 7). Además aparecen 


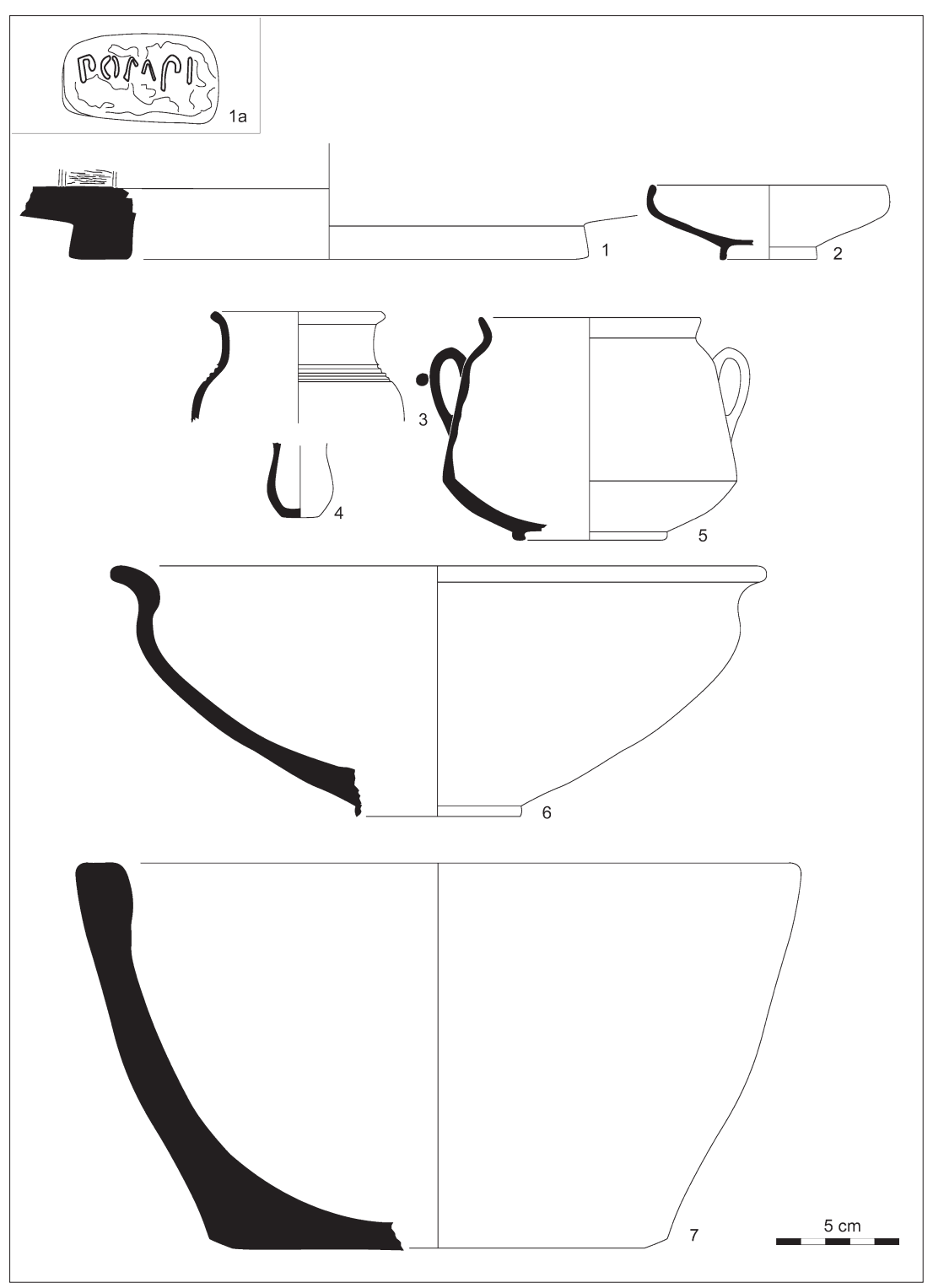

Fig. 7. Materiales cerámicos recuperados en la Fosa B (1-2) y cerámicas ibéricas procedentes de la Fosa A (3-7).

fragmentos de ánforas itálicas, hispánicas, tripolitana antigua, ebusitanas e incluso orientales (fig. 8), tres bases de Campaniense B (Lamboglia 1), junto a una interesante colección de TSI con los sellos de CN. ATEIVS y CN. ATEIVS MAHES y otros sudgálicos como IVNIVS (fig. 9), paredes finas (fig. 10), vidrio, millefiori, fragmentos de lucernas, pondera, pequeños ungüentarios y útiles de bronce como un tintinnabulum, un cochleari, cuatro volsellae o pinzas simples que tanto podían ser utilizadas en cirugía (Monteagudo 2000: 140-145) como elemento de aseo personal y moda (Gil 1997) y, en ocasiones, las hallamos también en contextos funerarios romanos (De la Barrera1989-1990: 242-243). También apareció un as del emperador Claudio, probablemente de los de imitación y cuchillos y otras piezas de hierro (fig. 11).

Además se halló una excepcional cabeza helenística de terracota, muy probablemente importada (fig. 12). Se trata de un busto femenino de $10 \times 17 \mathrm{~cm}$, realizado con arcilla que presenta una pasta dura y compacta, con pequeñas chamotas, algún punto ferruginoso, pequeños cuarzos y piedrecillas calcáreas de aproximadamente $1 \mathrm{~mm}$ que recuerdan a las producciones anfóricas de Ischia. La superficie 
Fig. 8. Ánforas recuperadas en la Fosa A, UE 14017-19.
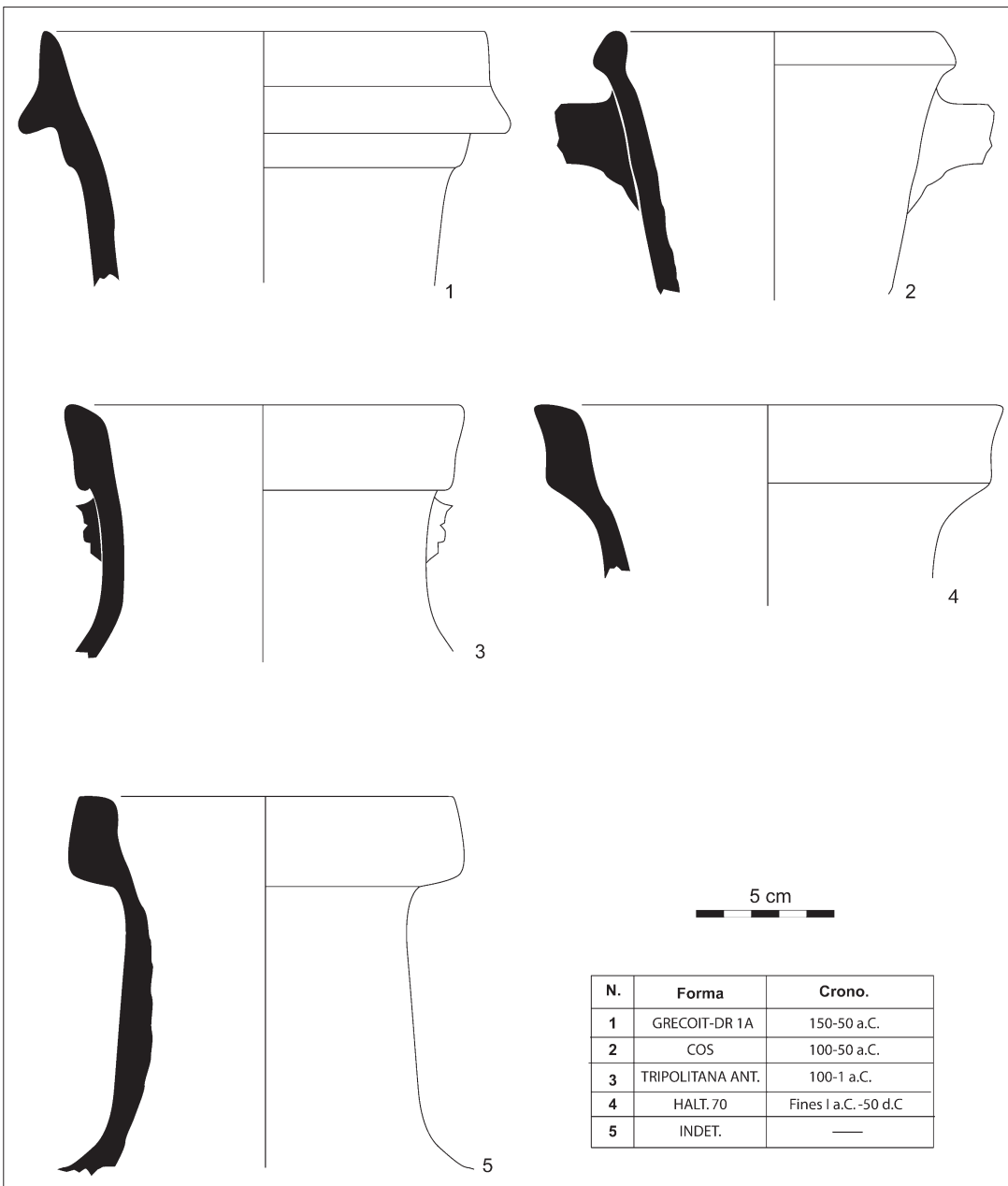

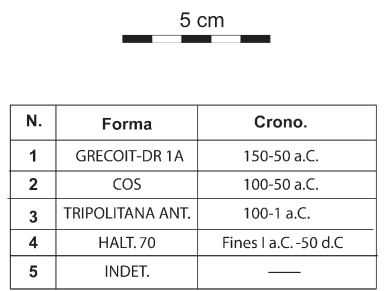

cabeza de idénticas características estilísticas durante el transcurso de las excavaciones de la calle Ruaya de Valencia. Aunque permanece inédita y depositada en los almacenes del Servicio Municipal de Arqueología de Valencia, se presentó una fotografía de la misma el 18 de Mayo de 2013 con motivo del día internacional de los Museos (Valencia antes de Valencia. De la prehistoria a los Cartagineses. Hallazgos en la calle Ruaya).

En cuanto a los restos de fauna presentes, éstos fueron escasos y estaban en muy mal estado de conservación. Entre ellos podía distinguirse un fragmento de cráneo de ciervo. También, se encontraron caracoles, una concha de berberecho, otra de almeja y algunos huesos de aceituna carbonizados. El conjunto, aunque tiene algún material del s. I a.C., presenta un repertorio que abarca toda la primera mitad del s. I d.C. 


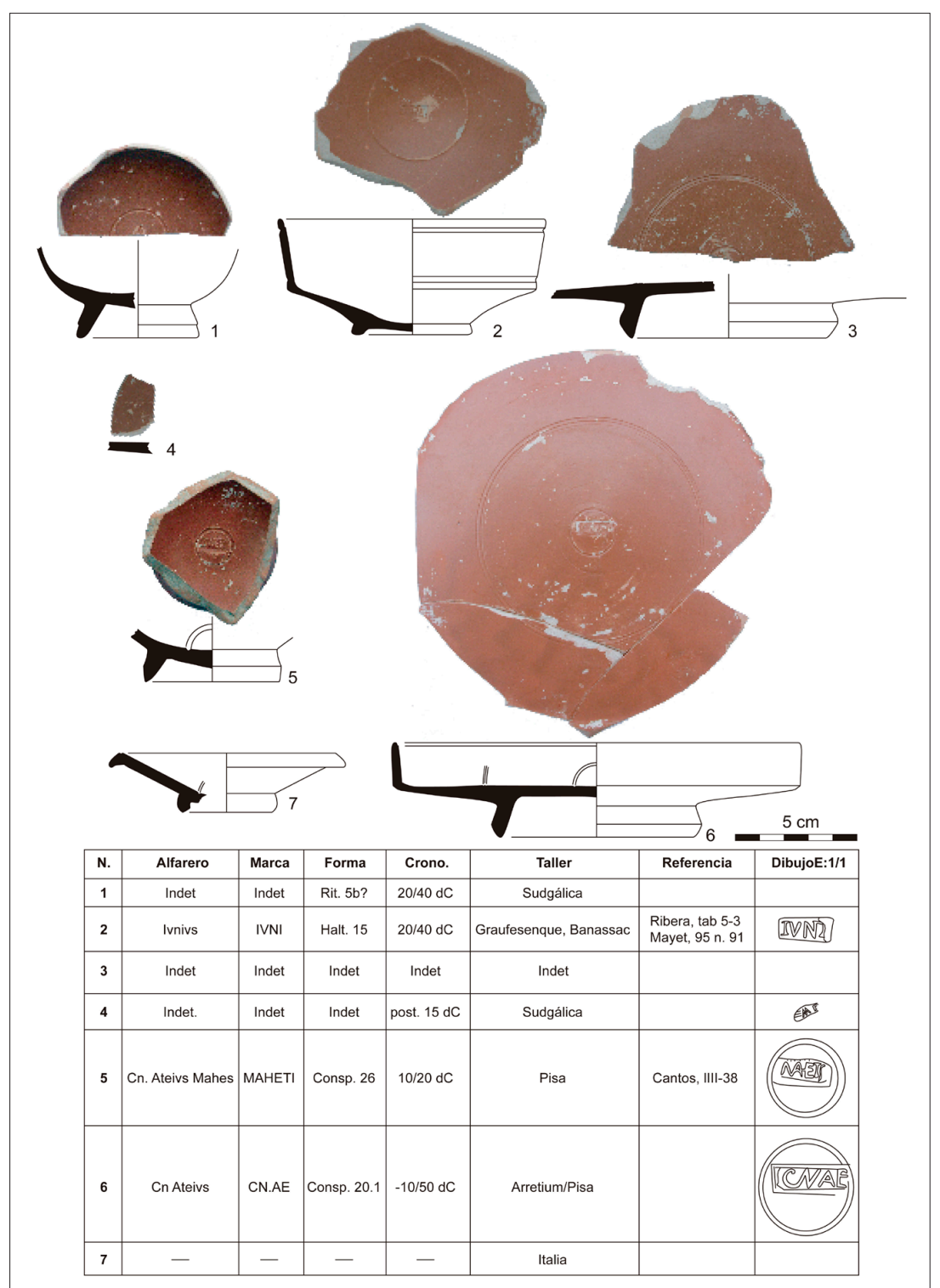

Fig. 9. Terra sigillata procedente de la Fosa A.

En general, a excepción de algunas piezas como los fragmentos de un vaso de vidrio millefiori, se trata de elementos bastante comunes que denotan cierta humildad en las gentes que la rellenaron y que en sí mismos no pueden ser considerados como indicativos de una actividad específica que otorgar al lugar.

Las estructuras situadas al norte de la fosa A parecen conformar un edificio de planta rectangular, dividido en dos espacios y cuyas paredes fueron de abobe y piedras. A él se debía acceder por una puerta ubicada al SO que daba paso a un área a cielo abierto o con techo leñoso, a juzgar por la falta de otros elementos de construcción, con un gran hogar situado en la zona central del mismo que pondría en relación el relleno de la fosa A con las actividades realizadas en el hogar (fig. 13).

Al SO de la fosa A existía un espacio cuadrangular, también a cielo abierto y cuyo elemento más significativo era la pequeña estructura rectangular pavimentada y para la que no hemos encontrado paralelos. Al conjunto podría accederse por una pequeña rampa identificada por el pequeño muro de contención y situada al $\mathrm{O}$ de esta singular estructura. 
Fig. 10. Paredes finas y fragmentos de lucernas de la Fosa A.

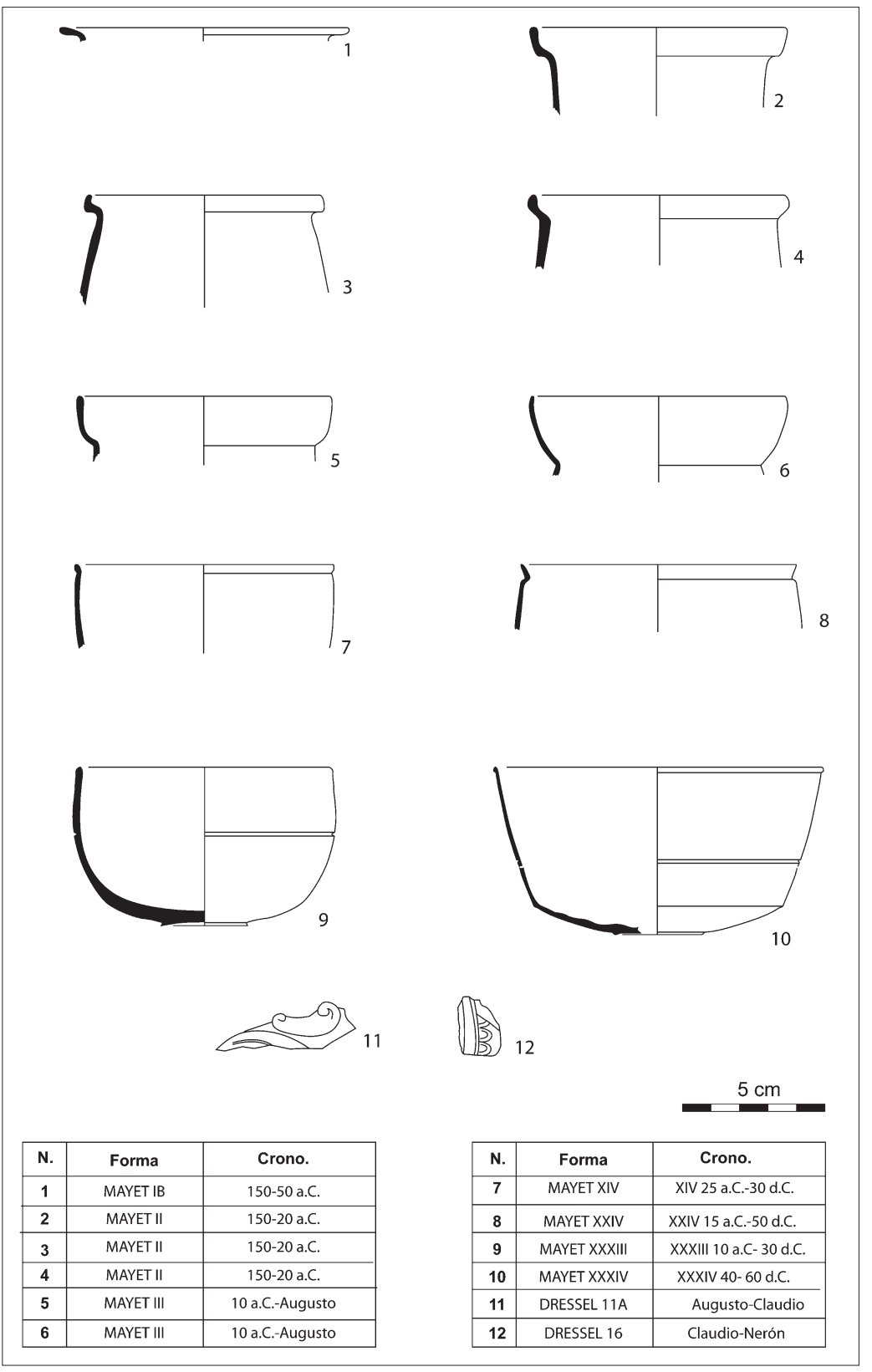

El mal estado de conservación así como la ambigüedad de los restos estructurales no permite plantear ninguna interpretación firme de los mismos. Por otra parte, los materiales procedentes de las fosas tampoco ayudan a establecer una actividad claramente diferenciada que atribuir al lugar. Desgraciadamente, aunque en el valle del Canyoles se conocen muchos yacimientos o concentraciones de materiales que abarcan la cronología en que se desarrolló nuestro yacimiento, lo cierto es que se han realizado muy pocas excavaciones sistemáticas y estudios en profundidad (Pascual y García 2010) que nos permitan comparar los restos que estamos tratando con otros localizados en la misma área de influencia. Desde luego, no se trata de los restos de una villa al estilo de algunas encontradas en territorium setabense como la de Els Alters en l'Ènova (Albiach 2006) o dels Horts en Vallada 


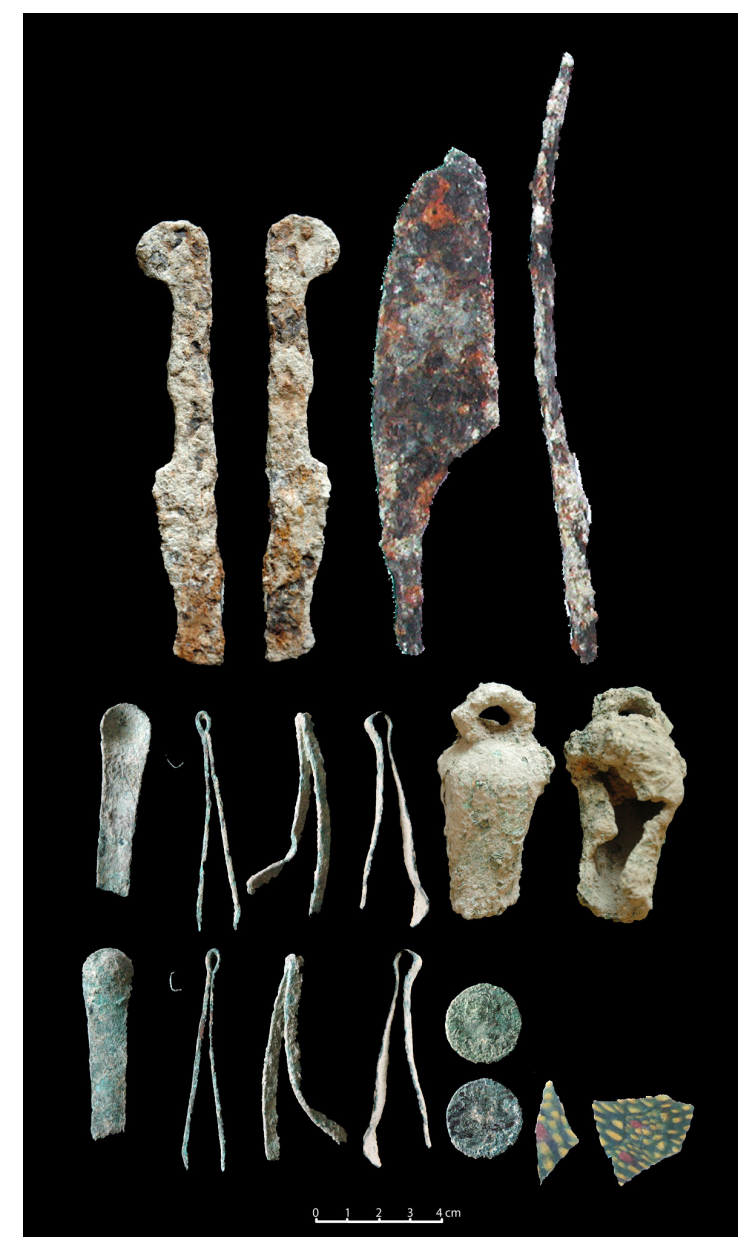

Fig. 11. Elementos de metal y fragmento de vidrio millefiori recuperados en la Fosa A.

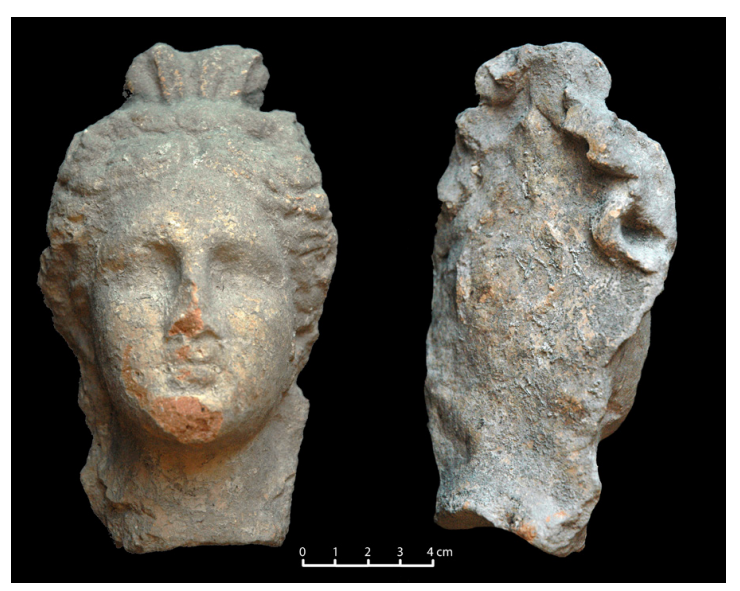

Fig. 12. Cabeza femenina en terracota.
(Martínez 1997) o como los de la taberna localizada junto a un tramo de la vía Augusta en Faldetes (Moixent) (García et al. 2012) que, además, son todos de cronología más reciente y los únicos, fuera de las grandes concentraciones urbanas o de población de la zona, en los que se han desarrollado intervenciones sistemáticas que han generado publicaciones.

Así pues, para procurar un sentido al conjunto, fundamentalmente contamos con los hallazgos que hemos podido documentar durante el transcurso de los trabajos de excavación y el posterior análisis de los materiales. Para ello, hay varias características a considerar.

En primer lugar, la pequeña envergadura del edificio localizado en el área NE que no parece extenderse más allá de lo que hemos podido representar en planta y que, sumado a la gran escasez de elementos de construcción tales como tégulas e ímbrices o la falta de restos de revestimientos de las paredes, parecen indicar que no se trata de un lugar habitado de manera constante o de un tipo de vivienda más o menos estable. Esta idea también viene reforzada por la propia composición de los rellenos de las fosas. Ambas son dos grandes agujeros excavados en el suelo y ninguna presenta restos de desperdicios orgánicos o grandes acumulaciones de fragmentos de cerámicas comunes. Por el contrario, en la base de la fosa B aparecieron depositadas un ánfora completa y una copa. Por su parte, en la fosa $\mathrm{A}$, los materiales aparecían en pequeñas concentraciones y, en algunos casos, han podido reconstruirse piezas. Además, el sedimento de esta última estaba formado esencialmente por cenizas. En este sentido, contamos también con las cenizas y materiales procedentes del hogar descubierto en la zona central del edificio que relacionan las actividades allí desarrolladas con el propio relleno de la fosa A. Parece que tras realizar la actividad que fuera en torno al hogar los restos de la misma eran arrojados a la fosa que, por otra parte, era más grande que el propio edificio en que se encontraba el hogar.

También contamos con la singular estructura 17 del sector SO cuya planta podría asimilarse a un pequeño altar al estilo de los lararios domésticos (Pérez 2008).

Todo ello, así como la amplia cronología evidenciada, parece indicar que se trata de un espacio acondicionado y frecuentado por las gentes que trabajaban los campos del entorno durante varias generaciones y nos hacen plantearnos la posibilidad que podríamos encontrarnos ante un espacio de culto rural. Si así fuera, sería plenamente romano y debió mantener una relación directa con los asentamientos rurales y la explotación agrícola de su 
Fig. 13. Estructuras del Sector A relacionadas con un santuario fechado en la primera mitad del s. I d.C. En rojo estructuras correspondientes a la fase anterior.

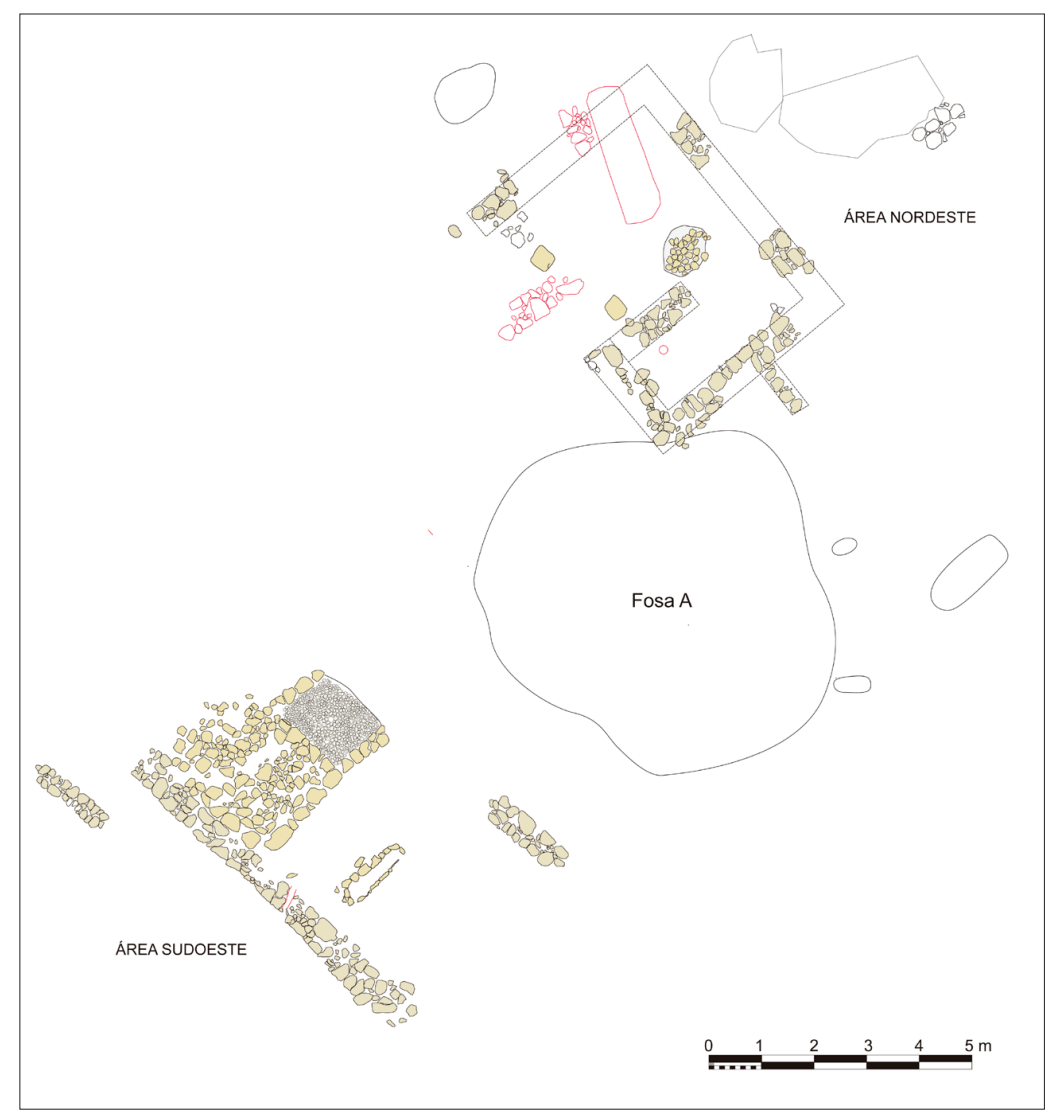

entorno. Aunque hay una considerable cantidad de cultura material ibérica o del ibérico tardío, lo cierto es que inicialmente estas estructuras se construyeron de nueva planta en la segunda mitad del s. II a.C. tal y como se desprende de los materiales recuperados de la fosa $\mathrm{B}$ y de las estructuras que a ella podrían asociarse y se modificó o reacondicionó en el cambio de era para, posteriormente, abandonarse a mediados del s. I d.C.

Desde el principio, aparecen materiales adscritos a una cultura eminentemente romana y las medidas del edificio en que se hallaba el hogar (20 por 15 pies romanos de $0,296 \mathrm{~m}$ ) también apuntan en esa dirección. La presencia de elementos indígenas, en lo que a materiales se refiere, podemos entenderla desde dos puntos de vista. Por una parte, la propia localización del sitio en un lugar densamente poblado desde, al menos, la Edad del Bronce (Molina y McClure 2004; Pascual y García 2010) y por otra, si aceptamos la sacralidad del emplazamiento, entendiéndolo como un factor de integración cultural (Marco 1996) o punto de encuentro entre dos culturas, en este caso la ibérica y la romana. En este sentido, resulta interesante resaltar que ya desde mediados del s. II a.C. Saetabis acuñó divisores de bronce que probablemente estuvieron relacionados con la presencia de negotiatores y colonos romanos o itálicos y las necesidades monetarias de los mismos, lo que implicaría el establecimiento de gentes itálicas en el valle desde un momento incipiente (Ripollès 2000).

\section{EXCAVACIONES EN EL SECTOR B}

\section{DESCRIPCIÓN E INTERPRETACIÓN DE LOS NIVELES Y ESTRUCTURAS}

En este sector, el nivel superficial se caracterizaba por estar formado con arcillas rojas, muy finas y sin inclusiones. Por debajo de éste aparecía un paquete de tierra de color amarillo verdoso (tap) con huellas de trabajo agrícola, probablemente correspondiente a labores de viñedo. Este nivel obedecía a depósitos de margas que 
procedían de la ladera que se encuentra al NE del sector. Por debajo había un nivel nuevamente de arcillas rojas localizado hacia el $\mathrm{O}$ del sector excavado, sin materiales arqueológicos y con escasas piedras de pequeño tamaño que cubría a una serie de estructuras realizadas con piedras de tamaño pequeño y mediano que hemos interpretado como bancal.

Se han identificado tres estructuras diferentes. La primera con una orientación SO-NE y 21 m de longitud mínima documentada en planta por un ancho medio de 1,20 $\mathrm{m}$ es la más significativa del área de intervención en el Sector B. En algunos puntos presentaba restos de pequeños fuegos que se habían producido sobre ella. La cara $S$ tenía una disposición de las piedras más cuidada y es en la que se concentraban las de mayor tamaño. En cambio, el límite $\mathrm{N}$ de la estructura era bastante irregular y las piedras, por lo general, eran pequeñas y no presentaban ordenación alguna (fig. 14).

Se realizaron un corte transversal y un alzado en el punto en el que parecía que mejor se conservaba la estructura original y pudimos comprobar que, en realidad, se encontraba dispuesta sobre un pequeño escalón del terreno siguiendo la curva de nivel de 228.405 m s.n.m. Se trataba de una construcción en seco con un alzado en torno a $40 \mathrm{~cm}$.

Otra de las estructuras localizadas estaba situada inmediatamente al $\mathrm{O}$ de la anterior y correspondía a una gran agrupación de piedras y cantos de tamaño medio dispuestos de modo aleatorio de 2,15 x 2 m de diámetro. Aunque se realizó un sondeo hasta llegar al nivel de arcilla que había por debajo, éste no proporcionó materiales ni definió estructura alguna. Resulta difícil de interpretar aunque probablemente no sean más que los restos de la

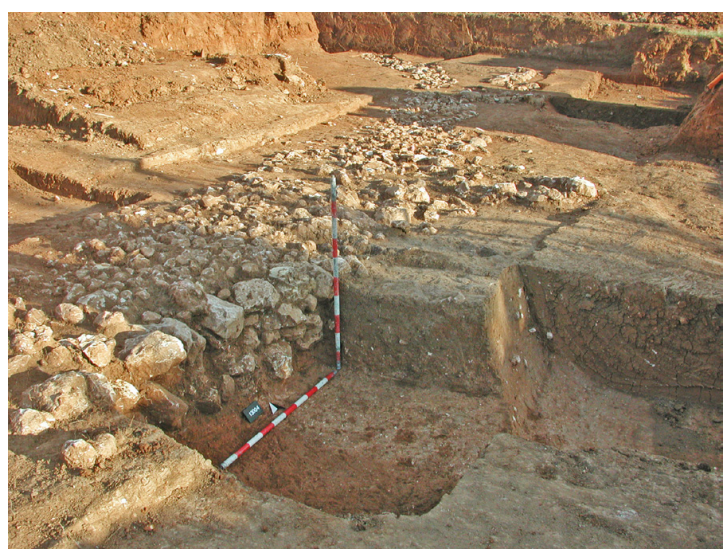

Fig. 14. Estructura de piedras interpretada como bancal. Sector B. acumulación de piedras que se usaron para realizar la estructura anterior o también pueda corresponder al lugar de acceso de un bancal inferior a otro superior.

Finalmente se documentó una alineación de mampuestos en seco que presentaba una única hilada de piedras de tamaño grande y 1,67 $\mathrm{m}$ de largo por $42 \mathrm{~cm}$ de ancho. Ésta se encontraba en la zona oriental de la excavación aproximadamente a $1 \mathrm{~m}$ al $\mathrm{S}$ de la primera y su funcionalidad no queda clara.

Asociado a estas estructuras encontramos un nivel de tierra arcillosa de color marrón oscuro, con escasas piedras y, relativamente, abundantes trozos cerámicos muy rodados y fragmentados que abarcan una amplia cronología con materiales que van desde el s. II a.C. hasta el II d.C. Este nivel solamente se encontraba al sur de las estructuras descritas, sobre un potente estrato de arcillas rojas $\mathrm{y}$, como más adelante veremos, tenía que ver con otro de idénticas características localizado en el Sector C.

\section{EXCAVACIONES EN EL SECTOR C}

\section{DESCRIPCIÓN E INTERPRETACIÓN DE LOS NIVELES Y ESTRUCTURAS}

Por debajo del nivel superficial había un potente paquete de tierra margo-arcillosa de color marrón claro, sin inclusiones abundantes y con escasos fragmentos cerámicos en su matriz. Este nivel, que corresponde a tierras revueltas por las últimas actividades agrícolas desarrolladas en el lugar, se encontraba cubriendo a una estructura de piedras y cantos de mediano y gran tamaño que presentaba una alineación NO-SE y por otra, a un gran nivel

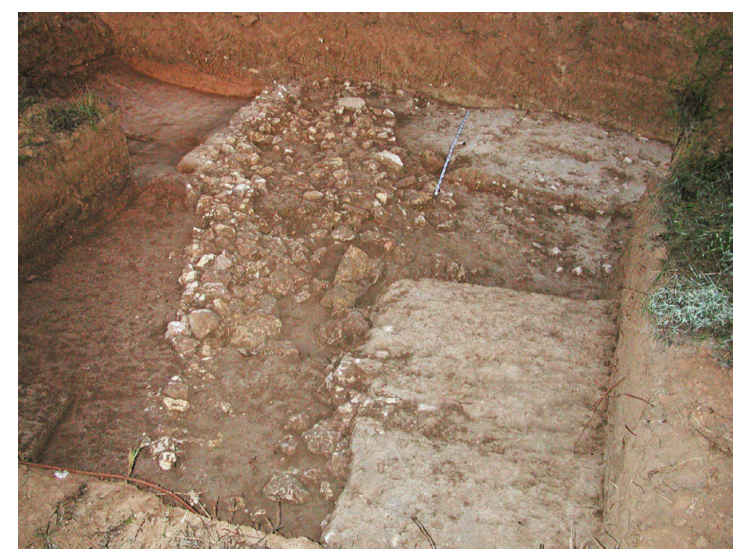

Fig. 15. Estructura de piedras interpretada como bancal. Sector C. 
de tierra margo-arcillosa, de color marrón oscuro y en el que abundaban trozos de cerámica rodados y muy fragmentados.

En cuanto a la estructura de piedras (fig. 15), todo indica que se trataba de un antiguo bancal, dispuesto aprovechando la curva de nivel en la que se encontraba. Era una agrupación de piedras y cantos más o menos alineados, trabados en seco y con un frente, el NE, bien dispuesto y de mayor alzado que el contrario.

Entre los materiales que aparecieron en el nivel de tierra marrón oscura se encontraban fragmentos de cerámicas tardoibéricas, común romana y algún fragmento de TSH que nos remiten a una amplia cronología que, a grandes rasgos, abarca desde el s. II a.C. hasta el II d.C. Este nivel oscuro parecía apoyarse sobre la estructura de piedras e incluso cubrirla. Debe corresponder al desmoronamiento y arrastre de un nivel que estuvo a una cota más elevada. En este sentido, nos parece interesante destacar que una inspección visual de la loma a los pies de la cual se encontraba la asociación de niveles y estructuras que hemos excavado, ha confirmado que en los actuales cortes de bancal, aproximadamente a $1 \mathrm{~m}$ de profundidad, aparece este mismo nivel marrón oscuro con cerámicas antiguas. De todo ello podemos deducir que, al menos la loma a cuyos pies encontramos estos niveles, debió estar abancalada ya desde el s. II o I a.C. y por tanto explotada desde el punto de vista agrícola.

Debajo del bancal encontramos una huella de besana con su relleno. Dada su ubicación parece que puede tratarse de los restos de una actividad agrícola en la zona anterior al abancalado del lugar.

\section{CONCLUSIONES}

El yacimiento se encuentra inmediatamente después de las faldas meridionales de Serra Plana, a los pies de la Lloma Ampla, entre el barranco del mismo nombre al $\mathrm{O}$ y el del Toll al E. Los Sectores A y C corresponden a dos pequeñas laderas formadas fundamentalmente por margas terciarias de la facies tap, mientras que el Sector B se encuentra en una depresión producida por un pequeño barranco y el sedimento está compuesto por arcillas de descalcificación procedentes de las faldas cretácicas de la Lloma Ampla. Asimismo, está a unos $300 \mathrm{~m}$ al $\mathrm{N}$ del camí de l'Alcúdia o del Carrascar y a $1 \mathrm{~km}$ al $\mathrm{N}$ de la autovía que atraviesa la comarca.

Ningún elemento permite plantear una interpretación firme de los restos encontrados. Sin embargo, una serie de indicios nos plantean la posibilidad de que nos encontremos ante un lugar de culto rural romano. Por un lado tenemos la pequeña estructura del área SO, para la que no hemos encontrado paralelos pero cuya tipología, en un contexto sacro, podría hacerla asimilable a un pequeño altar o espacio sagrado. Asimismo, aunque salvando las diferencias obvias, el edificio del sector NE recuerda, tanto por dimensiones como por planta, a otros espacios claramente sacros como el sacellum del Círculo Católico de Huesca (Asensio 2003). Por otro lado, las características y rellenos de las fosas, que no parecen remitir a un simple basurero al uso; finalmente, el propio emplazamiento de los restos en un lugar eminentemente rural.

Cabe, pues, la posibilidad de encontrarnos ante una zona presidida por un pequeño espacio consagrado alrededor de un altar, a cielo abierto y, muy probablemente cercado tal y como suele ser habitual en ese tipo de lugares cultuales. Podría corresponder, por tanto, a un espacio de culto rural a cielo abierto o sacellum (Castillo 2000) el cual deberíamos relacionar con la presencia en la región de colonos procedentes de Italia. En este sentido, es importante señalar que su construcción no se llevó a término aprovechando uno anterior o sobre los restos de un emplazamiento más antiguo, sino que se hizo de nueva planta, probablemente en la segunda mitad del s. II a.C. y estuvo funcionando hasta mediados del s. I d.C. Si los materiales de las fosas los relacionamos con ofrendas votivas denotarían, en general, cierta humildad de los oferentes y, por tanto, sería lógico pensar que este lugar fuera frecuentado por las personas que trabajaban las tierras de su entorno. Aunque, no obstante, debemos insistir en la ausencia total de dedicaciones o inscripciones que indiquen que se trata de vestigios con un sentido votivo y también en la complejidad del mundo religioso romano, cuyos ritos no fueron nunca universales y su relación con la religión y los lugares de culto, no está desprovista de ambigüedades (Burgaleta 1989; Revilla 2002), especialmente en el período republicano y en las regiones de origen de estos colonos donde, salvo excepciones, no parece que la intervención o influencia de Roma en las prácticas religiosas rurales fuera decisivamente de homogeneización oficial (Stek 2009).

En santuarios localizados en el área de Valencia, como Montaña Frontera en Sagunto, se constata la continuidad de un lugar sacro desde el Ibérico pleno donde el carácter romano del culto se inició en el s. I a.C. y continuó sin interrupción hasta el s. III d.C. (Nicolau 1998). Allí, ha podido establecerse que se encontraba bajo la advocación de Liber Pater (Ledo 2009), un dios fuertemente relacionado con los colonizadores romanos (Bruhl 1953). 
En la Montaña de Santa Bárbara, en el territorium saguntino, también se ha localizado un santuario hispano-romano con inicio en el s. I a.C. (Vicent 1979) que Corell ha propuesto estuviera dedicado a Apolo (Corell 1994).

Fuera o no un espacio de culto, este lugar habrá que entenderlo como un elemento más a la hora de tener en cuenta el incipiente proceso de colonización romano en esta zona. Un proceso que ya desde el s. II a.C. atrajo hacia las regiones Bética y Levantina una importante cantidad de emigrantes campanos o suritálicos no solo vinculados a las operaciones militares, sino también de civiles como consecuencia de la crisis del campo en Italia (Marín 1986-1987; Marín 1988). Todos ellos introdujeron nuevas formas de organización ajenas al mundo indígena y aportaron su religión llena de matices y complejidades.

Este espacio se encontraba rodeado de campos de cultivo, en un paisaje rural definido por el abancalado de la zona circundante y próximo a un importante eje de comunicación que atravesaba la comarca, al menos, desde la Edad del Bronce (Pascual y García 2010).

Todos los elementos que hemos identificado definen, pues, un paisaje rústico en el que, al menos desde la segunda mitad del s. II a.C. y hasta como mínimo el s. II d.C., queda patente el abancalado del terreno para el aprovechamiento agrícola de las faldas de las laderas y barranquitos circundantes. Entre los cultivos de la zona probablemente predominó el del olivo, al menos eso podríamos inferir del hecho de que tanto en el sector A como en el B aparecieron restos carbonizados de aceitunas así como de la propia naturaleza del paisaje que es apta para los cultivos de secano.

Con todo, podemos deducir que durante la segunda mitad del s. II a.C. se produjo, al menos en el área que hemos analizado, una importante transformación agrícola muy probablemente relacionada con el establecimiento y redistribución de tierras por parte de gentes itálicas. Si bien, con anterioridad y como parece deducirse de la huella de arado localizada bajo el bancal del sector C, las lomas circundantes estaban ya siendo explotadas desde un punto de vista agrario.

Guillermo Pascual Berlanga Arqueólogo N. 14336 del Colegio Oficial de Doctores y Licenciados en Filosofía y Letras y Ciencias de Valencia guillermo.pascual@uv.es

PAula Jardón Giner Dept. de Didàctica i Organització Escolar Universitat de València Paula.Jardon@uv.es

\section{NOTA}

1. La inscripción sufrió daños en el proceso de lavado y del dibujo quizás podría interpretarse BOMBI, pero cuando apareció era evidente que ponía POMPI.

\section{BIBLIOGRAFÍA}

ALBIACH, R.; DE MADARIA J. L. (2006): La villa de Cornelius (L'Ènova, València), Ministerio de Fomento (Adif), Valencia.

ASENSIO, J.A. (2003): El sacellum in antis del Círculo Católico de Huesca (Osca, Hispania Citerior). Un ejemplo precoz de arquitectura templaria romana en el valle del Ebro, $S A L D$ VIE 3, 93-127.

BRUHL, A. (1953): Liber Pater : Origine et expansion du culte dionysiaque à Rome et dans le monde romain, Bibliothèque des Écoles Françaises d'Athènes et de Rome, fasc. 175, París.

BURGALETA, F. J. (1989): Algunas cuestiones sobre la introducción de los cultos romanos en la Península Ibérica en época Republicana, Studia Historica (Historia Antigua) 7, Problemas de la Hispania Republicana, 119-129.

CANTOS, A. (2001-2002): Terra sigillata itálica y gálica de la quinta campaña de excavaciones en el Palao (Alcañiz, Teruel), SALDVIE II, 267-282.

CASTILLO, P. (2000): Las propiedades de los Dioses: los Loca Sacra, Iberia 3, 83-109.

CORELL, J. (1994): La "Muntanyeta de Santa Bárbara" (La Vilavella, Castellón) ¿Un santuario de Apolo?, Anuari de Filologia XVII, Secc. D. núm. 5, 155.

DE LA BARRERA, J. J. (1989-1990): Hallazgo de sepulturas de época romana en Mérida, Anas 2-3, 229-248.

GARCÍA Y BELLIDO, A. (1951): Esculturas romanas de Pollentia, AEspA 34, 83-84, 53-65.

GARCÍA Y BELLIDO, A. (1958): Catálogo de los retratos romanos de Carmona, la antigua Carmo, en la Bética, AEspA 31, 97-98, 205-211.

GARCÍA Y BELLIDO, A. (1990): Arte Romano, Madrid.

GARCÍA BORJA, P.; LÓPEZ, D.; JIMÉNEZ, J. L. (eds.) (2012): Al pie de la vía Augusta. El yacimiento romano de Faldetes (Moixent, Valencia), Enagás-Acuamed, Alcoy.

GIL, E. (1997): El instrumental metálico de época romana en Álava. Testimonio de actividades domésticas y profesionales, $I s$ turitz $9,535-563$.

LEDO, A. (2009): El santuario de Montaña Frontera y la producción de vino en el Sagunto Prerromano, ELEA 9, 479-502.

MARCO, F. (1996): Romanización y aculturación religiosa: los santuarios rurales, A cidade o Mundo: Romanización e cambio Social (S. Rebordea, P. López, eds.), Xinzo de Limia, Universidad de Salamanca.

MARÍN, M. A. (1986-1987): La emigración itálica a Hispania en el siglo II a.C., Studia Historica (Historia Antigua), Vols. IVV, núm. 1, 53-63. 
MARÍN, M. A. (1988): Emigración, colonización y municipalización en la Hispania Republicana, Granada.

MARTÍNEZ GARCÍA, J. M. (1997): La villa romana de Els Horts: tres campañas de excavaciones arqueológicas (19871990), Monografías de Vallada 4, Associació Valladina de Cultura i Investigació, Vallada.

MAYET, F. (1978): Importation des sigillées a Mérida au I siècle de notre ère (sigillées italiques et gauloises), Conimbriga XVII, 80-107.

MOLINA, LL.; McCLURE, S. (2004): Cànyoles archaeological survey Project. Resultados preliminares, Recerques del Museu d'Alcoi 13, 149-170.

MONEO, T. (2003): Religio Ibérica. Santuarios, ritos y divinidades, Bibliotheca Archaeologica Hispana 20, Madrid.

MONTEAGUDO, L. (2000): La cirugía en el Imperio Romano, Anuario Brigantino 23, 85-150.

NICOLAU, R. (1998): Un santuario iberorromano saguntino situado en la montaña Frontera (Sagunto, Valencia), AAC 9, 25-49.

PÉREZ RUIZ, M. (2008): Aproximación al culto doméstico en la Hispania Romana: algunas consideraciones, Bollettino di Archeologia on line. Volume Speciale. Roma 2008. Internacional Congress of Clasical Archaeology. Meetings Between Cultures in the Ancient Mediterranean. Ministero per i Beni e l'Attività Culturali.

PASCUAL, G.; GARCÍA BORJA, P. (2010): El poblamiento en la comarca de La Costera (Valencia) desde el Neolítico hasta época romana. Yacimientos arqueológicos y vías de comunicación, APL XXVIII, 301-325.

REVILLA, V. (2002): Santuarios, élites y comunidades cívicas: consideraciones sobre la religión rural en el Conventus Tarraconensis, Religión y propaganda política en el mundo romano (F. Marco Simón, F. Pina Polo, J. Remesal Rodríguez, eds.), Col.lecció Instrumenta 12, 189-226.

RIBERA, A. (1988-1989): Marcas de Terra Sigillata del Tossal de Manises, LVCENTVM VII-VIII, 171-204.

RIBERA, A.; TSANTINI, E. (2008): Las ánforas del mundo ibérico, $\mathrm{Ce}$ rámicas hispanorromanas. Un estado de la cuestión (D. Bernal, A. Ribera, eds.), XXVI Congreso Internacional de la Asociación Rei Cretariae Romanae Fautores, Cádiz, 617-634.

RIPOLLÈS, P. P. (2000): La monetización del mundo Ibérico, Ibers. Agricultors, artesans i ramaders i comerciants. III Reunió sobre Economia en el mon Ibèric (C. Mata y G. Pérez, eds.), SAGVNTVM-PLAV, Extra 3, 329-344.

SCHEID, J. (1997): Comment identifier un lieu de culte? Pour un inventaire des lieux de culte de l'Italie Antique, Cahiers $d u$ Centre Gustave Glotz 8, 51-59. DOI:http://dx.doi.org/10.3406/ccgg.1997.1432

STEK TESSE, D. (2009): Cult places and change in Republican Italy. A contextual approach to religious aspects of rural society after the Roman conquest, Amsterdam Archaeological Studies 14, Amsterdam University Press.

VICENT, J. A. (1979): Excavacions al santuari Hispano Romà de Santa Bàrbara, CPAC 6, 181-221. 